\title{
Hip and other fragility fracture incidence in real-world teriparatide-treated patients in the United States
}

\author{
R. T. Burge ${ }^{1,2} \cdot$ D. P. Disch ${ }^{1} \cdot$ S. Gelwicks ${ }^{1}$ X. Zhang ${ }^{1} \cdot$ J. H. Krege ${ }^{1}$
}

Received: 1 July 2016 / Accepted: 15 December 2016 / Published online: 27 December 2016

(C) The Author(s) 2016. This article is published with open access at Springerlink.com

\begin{abstract}
Summary This study demonstrates real-world effectiveness of teriparatide in reducing the risk of hip and other fragility fractures. Fracture incidence significantly decreased as adherence and persistence increased for any clinical, vertebral, nonvertebral, and hip fractures among patients who were observed for 2 years after teriparatide initiation.

Introduction Examine the relationship of treatment adherence and persistence to teriparatide with hip and other fractures. Methods Truven MarketScan Research Databases, 2004 through 2014, provided teriparatide users $\geq 18$ years old with continuous coverage 12 months pre- and 24 months postteriparatide prescription. Adherence (medication possession ratio, MPR) groups were defined as high $(\geq 0.80)$, medium $(0.50 \leq \mathrm{MPR}<0.80)$, and low $(<0.50)$. Persistence, allowing for $\leq 90$-day gaps between prescriptions, was defined as $1-6$, $7-12,13-18$, and 19-24 months. Fracture incidence was summarized and compared by using ANOVA and logistic regression models; the effects of adherence were examined with Cox proportional hazard models with time-dependent covariates for teriparatide exposure.

Results Among 14,284 teriparatide subjects, mean age was 68.4 years, $89.8 \%$ were female, and $29.6 \%$ had a fracture in the previous year; these characteristics were similar across
\end{abstract}

Electronic supplementary material The online version of this article (doi:10.1007/s00198-016-3888-9) contains supplementary material, which is available to authorized users.

R. T. Burge

burge_russel_thomas@lilly.com

1 Eli Lilly and Company, Lilly Corporate Center, Indianapolis, IN 46285, USA

2 University of Cincinnati, Cincinnati, OH, USA
MPR and persistence groups. The effects of adherence and persistence to teriparatide were statistically significant $(P<.001)$ for all fracture types except wrist $(P \geq .125)$. By logistic regression, high vs low adherence was associated with reduced risk for any $(\mathrm{OR}=0.67 ; P<.001)$; vertebral $(\mathrm{OR}=0.64 ; P<.001)$; nonvertebral $(\mathrm{OR}=0.71 ; P<.001)$; and hip fractures $(\mathrm{OR}=0.52 ; P<.001)$ and longer $(19$ 24 months) vs shorter persistence ( $1-6$ months) was associated with reduced risk for any $(\mathrm{OR}=0.63, P<.001)$; vertebral $(\mathrm{OR}=0.56, P<.001)$; nonvertebral $(\mathrm{OR}=0.69, P<.001)$; and hip fractures $(\mathrm{OR}=0.48, P<.001)$. Cox models revealed a significantly reduced risk between high and low adherence for any $(\mathrm{OR}=0.69, P<.001)$; vertebral $(\mathrm{OR}=0.60, P<.001)$; nonvertebral $(\mathrm{OR}=0.77, P<.001)$; and hip fractures $(\mathrm{OR}=0.55, P<.001)$.

Conclusion Fracture incidence significantly decreased as persistence and adherence to teriparatide increased.

Keywords Fracture risk reduction · Hip fracture .

Nonvertebral fracture $\cdot$ Real-world effectiveness $\cdot$ Teriparatide

\section{Introduction}

In the USA, osteoporosis is an important health concern in the population of approximately 54 million people over the age of 50 [1] and is characterized by reduced bone mineral density (BMD), deterioration in bone microstructure, and increased risk of fracture [2]. Osteoporosis is the primary underlying cause of fractures in the elderly and contributes more than 2 million fractures each year [3]. Fracture incidence increases with age for hip, vertebral, and most nonvertebral sites [4]. Total incident hip fractures are expected to increase with the aging of the population, even though recent studies suggest that hip fracture incidences show secular declines in the USA [5], Canada [6], and Europe [7, 8] or 
may be leveling off [9]. In the USA from 2015 to 2025, the total annual number of incident fractures is predicted to rise by $21 \%$ (from 2.51 to 3.04 million), and total hip fractures are projected to increase by $26 \%$ (from 335,000 to 447,000 ), assuming constant incidence, or to increase by $16 \%$, assuming declining incidence [3].

Hip fractures are associated with increased risk of further fractures, increased morbidity and mortality, and profound temporary or permanent impairment of independence and quality of life [10-14].

Teriparatide (parathyroid hormone [1-34] [recombinant DNA origin]) stimulates new bone formation on trabecular and cortical bone surfaces by preferential stimulation of osteoblastic activity over osteoclastic activity. In humans, the anabolic effects of teriparatide are manifest as an increase in skeletal mass, an increase in markers of bone formation and resorption, and an increase in bone strength [15-17]. Teriparatide is approved for treating postmenopausal women with osteoporosis at high risk for fracture, for increasing bone mass in men with primary or hypogonadal osteoporosis at high risk for fracture, and for treating men and women with glucocorticoid-induced osteoporosis at high risk for fracture $[18,19]$. Teriparatide has been shown to reduce the risk of vertebral and nonvertebral fractures in randomized clinical trials $[15,20]$, in real-world observational studies [21, 22], and in retrospective claims database studies [23]. However, real-world evidence is lacking on the effectiveness of teriparatide in reducing risk of hip fractures.

Proper adherence to medications is essential for achieving good outcomes [24]. Similar to adherence for other chronic therapies, adherence to osteoporosis treatments is suboptimal: more than half of patients failed to comply or persist with their medication regimens at 1 year [24-29]. Teriparatide therapy persistence at 12 months has been reported to range from 57 to $77 \%[21,23,30,31]$.

Previous research on teriparatide adherence and persistence supports the hypothesis that longer duration and higher rates of adherence are associated with improved patient outcomes [20-23, 32-35]. Moreover, retrospective claims database studies have reported lower nonvertebral fracture incidence with longer exposures [23, 33, 34]. In the 2012 claims database study by $\mathrm{Yu}$ and colleagues, all-clinical, clinical vertebral, and nonvertebral fracture incidence were statistically significantly lower for more persistent and adherent patients than for those patients with the least persistence and worst adherence [23]. Because most studies of teriparatide have a relatively small number of fractures, additional information from a larger group of patients treated with teriparatide might be helpful to clarify the effects of teriparatide on fractures. Furthermore, previous studies have only examined the association between teriparatide exposure and fracture incidence and have not adequately evaluated the real-world effectiveness or possible causality of teriparatide in terms of reducing the risk of incident fractures. Therefore, our study extends $\mathrm{Yu}$ and colleagues' 2012 claims database study by using 11 years of on-market and more recent data to examine both the association and the real-world effectiveness of teriparatide treatment on the incidence of hip and other fractures in the United States.

\section{Materials and methods}

\section{Data source}

This study was conducted by using the Truven MarketScan Research Databases from 01 January 2004 to 31 December 2014.

\section{Study population}

The study population consisted of new teriparatide (parathyroid hormone [1-34] [recombinant DNA origin]) users aged 18 years and older. New users were defined as having no pharmacy claims for teriparatide during the 12 months before the first prescription dispensed and at least 1 prescription filled for teriparatide. The date the first prescription was dispensed was defined as the index date, with the index teriparatide prescription occurring between 1 January 2005 and 31 December 2012. New users were required to have continuous medical and pharmacy coverage 12 months before and 24 months after the first teriparatide prescription was dispensed. Patients diagnosed with Paget disease were identified by International Classification of Diseases, 9th Revision, Clinical Modification (ICD-9-CM) code 731.0 and/or specific medication dosing (alendronate sodium $40 \mathrm{mg}$ daily and risedronate sodium $30 \mathrm{mg}$ daily) and were excluded from the study population.

Baseline patient characteristics, including age and gender, were recorded as of the date of the first teriparatide prescription. Clinical characteristics included assessments of health status, measured by the Deyo Charlson Comorbidity Index (CCI), whether a BMD test had been performed, and the number of fractures reported during the 12 months before the first teriparatide prescription. Confounding medications included osteoporosis medications (bisphosphonates, selective estrogen receptor modulator [SERM], calcitonin, denosumab, and hormone therapy) and medications known to be associated with bone loss or risk of fracture (glucocorticoids, hormone deprivation therapy, anticonvulsants, and immunosuppressants) $[26,36,37]$. All baseline characteristics were used as covariates in the multivariate regression models. All covariates were categorical variables except age and Deyo CCI score, which were continuous variables. 


\section{Adherence and persistence}

Medication adherence was measured by the medication possession ratio (MPR), defined as the sum of days of supply dispensed divided by the total number of days of the postindex period. An MPR greater than or equal to 0.80 was defined as high, $0.50 \leq \mathrm{MPR}<0.80$ was defined as medium, and $<0.50$ was defined as low adherence for osteoporosis medication [23-25].

Medication persistence was measured as teriparatide use with gaps in treatment of less than or equal to 90 days, where the gap was measured from last date of therapy (date of last day of drug supply) to the beginning date of the subsequent therapy prescription. All patients without gaps in teriparatide of more than 90 days were considered "persistent." Medication persistence was calculated as a categorical variable, and patients were entered into 1 of 4 persistence groups: 1-6, 7-12, 13-18, and 19-24 months. Medication persistence categorical variables were used in the descriptive and multivariate regression analyses.

\section{Fractures}

New incident fractures were identified by a claims-based algorithm at the 3-digit level of an ICD-9-CM code (see Online Resource 1). Fracture sites were categorized as any, vertebral, nonvertebral, hip, and wrist. Pathological fractures were included on the basis of the recommendation by Curtis and colleagues from epidemiologic studies of osteoporotic fractures [38]. Fractures that occurred after 90 days from the index date were considered incident fractures to provide sufficient time for therapeutic effects from teriparatide to begin. The 90day interval for onset of teriparatide effect is supported by work from Bonafede et al. using the same claims database [34]; during the year prior to teriparatide, $25.6 \%$ of the patients had fragility fracture claims and this approximate rate of fracture continued during the initial 90 days of teriparatide, but was lower thereafter [34, 35]. Hip fractures were identified by fracture diagnoses from inpatient admission claims. Vertebral fractures were identified by spine imaging tests within 30 days of fracture diagnoses. Nonvertebral and other fractures were identified from the primary ICD-9-CM codes on inpatient or outpatient admission claims. Subsequent fracture diagnoses could be claimed if the new claim was $>180$ days from the original fracture.

\section{Statistical methods}

SAS version 9.2 (SAS Institute Inc., Cary, NC, USA) was used for analytic file construction and all statistical analyses. Descriptive statistics for baseline and clinical characteristics, medication use, and previous fracture history were reported for the total study population and by MPR and persistence groups. Mean and standard deviation were reported for continuous variables, and number and percentage were reported for categorical variables. Means were tested using analysis of variance (ANOVA); percentages were tested using chi-square tests.

Unadjusted fracture incidence per 1000 patient years (PYs) were reported by fracture type and compared using ANOVA. The association between teriparatide exposure, based on persistence and adherence categories, and incident fractures was evaluated by using logistic regression analyses performed by fracture type (any, vertebral, nonvertebral, hip, and wrist) for modeling the probability of fractures over 24 months, adjusted for MPR and persistence in a time-invariant manner, and baseline covariates. Odds ratios (OR), 95\% confidence intervals, and associated $P$ values were reported for all the variables included in the logistic regressions, as were the type III analyses of effects for categorical variables with more than two categories.

Real-world effectiveness of adherence to teriparatide therapy on particular fracture site risk, by fracture type (any, vertebral, nonvertebral, hip, and wrist), was analyzed with Cox proportional hazard models using time-dependent cumulative adherence of teriparatide (censored at time of first outcome fracture or 24 months), adjusting for occurrence of other fractures (yes/no) preceding the main fracture outcome and adjusting for all baseline covariates used in logistic regression models above. The dependent variable in each model was time to the first incident fracture, and patients' adherence levels (low, moderate, or high) were calculated from the index date in cumulative 30 -day intervals. When a fracture occurred, the cumulative MPR for the period preceding the fracture was applied.

In real-world settings, a source of possible confounding is the "healthy adherer" effect or "adherence bias," whereby patients who are more adherent to medications may differ in important health-seeking behaviors and other aspects that affect outcomes from those who are not adherent to their medications. This phenomenon may lead to biased estimates of treatment effects when health status and healthy behaviors are not measured and adjusted for in the analyses. Claims databases (including the Truven MarketScan Research Databases used in this study) have limited or insufficient measures of health status and healthly lifestyle behaviors. Therefore, we conducted diagnostic tests for potential healthy adherer bias using control outcomes hypothesized to be unrelated to osteoporosis or teriparatide's treatment effects [39, 40]. As proxy measures, differences in these outcomes between adherence groups would reflect underlying, unmeasured differerences in health status and/or healthy behaviors. The control outcomes or "falsification" endpoints used to test for differences by teriparatide persistence and adherence groups included the six most frequent hospital admissions (expected to be unrelated to osteoporosis or teriparatide's effects) 
during the post-index period (i.e., those with primary ICD-9CM diagnoses of 486 [pneumonia, organism unspecified]; 491.21 [obstructive chronic bronchitis, with [acute] exacerbation]; 599.0 [urinary tract infection, site not specified]; 427.31 [atrial fibrillation]; 414.01 [coronary atherosclerosis of native coronary artery]; or 038.9 [unspecified septicemia]) (see Online Resource 2, 3, 4).

\section{Results}

There were 14,284 new teriparatide users aged 18 years or older reported in this study (Fig. 1). The numbers of patients in the low-, medium-, and high-MPR groups were 5469 (38.3\%), $2442(17.1 \%)$, and $6373(44.6 \%)$, respectively (Table 1). The numbers of patients in the $1-6,7-12,13-18$, and 19-24 months persistence groups were 3916 (27.4\%), 1968 (13.8\%), 1842 (12.9\%), and 6558 (45.9\%), respectively (Table 2). Baseline characteristics included mean age 68.35 years, $89.8 \%$ female, and $29.6 \%$ had a previous fracture (Table 1). The baseline Deyo CCI score was significantly different across MPR groups, with scores higher (representing worse health scores) in the low-MPR group (1.09) than in the high-MPR group (0.90). The frequency of patients who had a BMD test prior to beginning teriparatide was significantly greater in the high-MPR group $(85.0 \%)$ than in the lowMPR group (77.7\%). Baseline glucocorticoid and anticonvulsant use was significantly more common in the low-MPR group (44.2 and $18.8 \%$, respectively) than in the high-MPR group (37.9 and $15.1 \%$ ), and baseline bisphosphonate and SERM use was more common in the high-MPR group (59.3 and $11.0 \%$, respectively) than in the low-MPR group (43.2 and $8.4 \%$, respectively) (all $P<.001$; Table 1). Similar baseline results were observed across persistence groups; Deyo CCI scores were highest in the 1-6-month persistence group (1.15), BMD test frequency was highest in the 19-24-month persistence group (85.0\%), glucocorticoid and anticonvulsant use was most common in the 1-6-month persistence group (45.3 and $19.5 \%$, respectively), and bisphosphonate and SERM use was most common in the 19-24-month persistence group (58.9 and $11.0 \%$, respectively) (all $P<.001$; Table 2 ).

The mean (SD) exposure to teriparatide was 431.7 (260.2) days. The unadjusted incidence per 1000 PYs by MPR group for any clinical fracture ranged from 82.9 (low MPR) to 55.6 (high MPR). Fracture incidence per 1000 PYs by MPR group is displayed graphically in Fig. 2a. The unadjusted incidence per 1000 PYs by persistence group for any clinical fracture ranged from 91.2 (1-6 months) to 55.5 (1924 months). Fracture incidence per 1000 PYs by persistence group is displayed graphically in Fig. $2 \mathrm{~b}$. The proportion of patients with one fracture or with multiple fractures generally decreased as MPR or persistence increased for all fracture types except wrist fracture (see Online Resource 5).

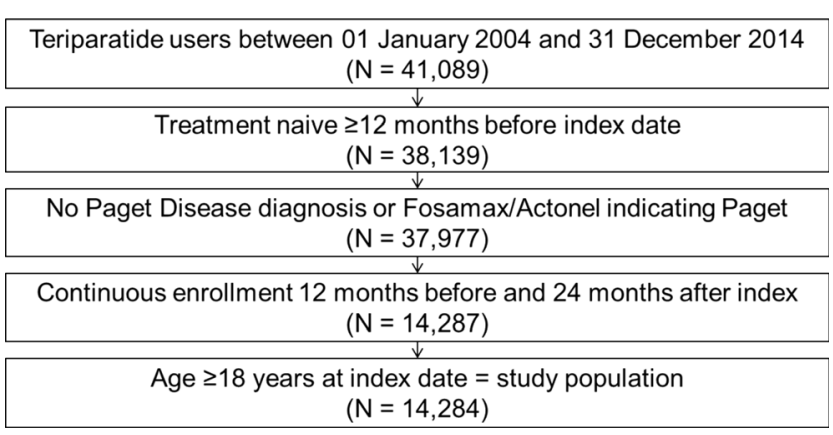

Fig. 1 Patient selection

The results from the logistic regression models indicate that the effects of adherence and persistence were statistically significant $(P<.001)$ for all fracture types except wrist fracture $(P \geq .125)$ (Table 3). Furthermore, high adherence (MPR) was associated with significantly lower risk than low adherence for any fracture $(\mathrm{O}=0.67 ; P<.001)$, vertebral fracture $(\mathrm{OR}=0.64 ; P<.001)$, nonvertebral fracture $(\mathrm{OR}=0.71$; $P<.001)$, and hip fracture $(\mathrm{OR}=0.52 ; P<.001)$. High and medium adherence compared to low adherence was not associated with reduced risk for wrist fracture (Table 3). Patients with longer persistence (19-24 months) were significantly less likely than patients with shorter persistence (1-6 months) to have any fracture $(\mathrm{OR}=0.63, P<.001)$, vertebral fracture $(\mathrm{OR}=0.56, P<.001)$, nonvertebral fracture $(\mathrm{OR}=0.69$, $P<.001)$, and hip fracture $(\mathrm{OR}=0.48, P<.001$, Table 3$)$.

In Cox proportional hazard modeling (Table 4 ), the effect of adherence to teriparatide was statistically significant $(P \leq .002)$ for all fracture types except wrist fracture $(P=.55)$. In addition, significantly lower risk was seen for any fracture $(\mathrm{OR}=0.79, P=.001)$ and vertebral fracture $(\mathrm{OR}=0.68, P<.001)$ for medium adherence than for low adherence and for any fracture $(\mathrm{OR}=0.69, P<.001)$, vertebral fracture $(\mathrm{OR}=0.60, P<.001)$, nonvertebral fracture $(\mathrm{OR}=0.77, P<.001)$, and hip fracture $(\mathrm{OR}=0.55$, $P<.001$ ) for high adherence than for low adherence (see Online Resource 6 for a complete presentation of all factors in the model; these results were similar to those seen with the logistic regression).

After stopping teriparatide (a treatment gap of at least 90 days), use of osteoporosis medications other than teriparatide was $45.1 \%$ ( $31.8 \%$ bisphosphonate) in the 1 to 6-month group, $36.9 \%$ (23.8\% bisphosphonate) in the 7 to 12-month group, $32.6 \%$ (20.5\% bisphosphonate) in the 13 to 18 -month group, and $14.6 \%$ (8.1\% bisphosphonate) in the 19-24-month group. The control outcomes analyses revealed inconsistent evidence regarding potential healthy adherer bias. In two of the six hospital admission types, there were statistically significant differences in the incidence per 1000 PYs across the adherence and persistence groups (urinary tract infection), while coronary athlerosclerosis of native coronary 
Table 1 Baseline characteristics by MPR group

MPR

\begin{tabular}{|c|c|c|c|c|c|}
\hline & & & \multirow[b]{2}{*}{$P$ value } \\
\hline & Total $(N=14,284)$ & Low $(N=5469)$ & Medium $(N=2442)$ & $\operatorname{High}(N=6373)$ & \\
\hline \multicolumn{6}{|l|}{ Age, years } \\
\hline Age, mean (SD) & $68.35(12.01)$ & $68.06(12.91)$ & $67.56(12.00)$ & $68.90(11.15)$ & $<.001$ \\
\hline Age group, $N(\%)$ & & & & & $<.001$ \\
\hline $18-44$ & $284(2.0)$ & $171(3.1)$ & $52(2.1)$ & $61(1.0)$ & \\
\hline $45-54$ & $1445(10.1)$ & $650(11.9)$ & $263(10.8)$ & $532(8.3)$ & \\
\hline $55-64$ & $4220(29.5)$ & $1506(27.5)$ & $794(32.5)$ & $1920(30.1)$ & \\
\hline $65-74$ & $3299(23.1)$ & $1146(21.0)$ & $550(22.5)$ & $1603(25.2)$ & \\
\hline $75-84$ & $3845(26.9)$ & $1473(26.9)$ & $590(24.2)$ & $1782(28.0)$ & \\
\hline$\geq 85$ & $1191(8.3)$ & $523(9.6)$ & $193(7.9)$ & $475(7.5)$ & \\
\hline \multicolumn{6}{|l|}{ Sex, $N(\%)$} \\
\hline Female & $12,822(89.8)$ & $4904(89.7)$ & $2207(90.4)$ & $5711(89.6)$ & .55 \\
\hline Male & $1462(10.2)$ & $565(10.3)$ & $235(9.6)$ & $662(10.4)$ & \\
\hline \multicolumn{6}{|l|}{ Clinical characteristics } \\
\hline BMD test (yes/no), $N(\%)$ & $11,722(82.1)$ & $4249(77.7)$ & $2058(84.3)$ & $5415(85.0)$ & $<.001$ \\
\hline Previous fracture (yes/no), $N(\%)$ & 4235 (29.6) & $1593(29.1)$ & $767(31.4)$ & $1875(29.4)$ & .11 \\
\hline Deyo CCI, mean (SD) & $0.99(1.42)$ & $1.09(1.49)$ & $1.02(1.44)$ & $0.90(1.35)$ & $<.001$ \\
\hline \multicolumn{6}{|l|}{ Confounding medication, $N(\%)$} \\
\hline Glucocorticoids & $5872(41.1)$ & $2417(44.2)$ & $1040(42.6)$ & $2415(37.9)$ & $<.001$ \\
\hline Hormone deprivation & $154(1.1)$ & $58(1.1)$ & $27(1.1)$ & $69(1.1)$ & .98 \\
\hline Anticonvulsants & $2450(17.2)$ & $1029(18.8)$ & $458(18.8)$ & $963(15.1)$ & $<.001$ \\
\hline Immunosuppressants & $1367(9.6)$ & $526(9.6)$ & $260(10.6)$ & $581(9.1)$ & .09 \\
\hline \multicolumn{6}{|l|}{ Other OP medication, $N(\%)$} \\
\hline Bisphosphonates & $7392(51.8)$ & $2360(43.2)$ & $1255(51.4)$ & $3777(59.3)$ & $<.001$ \\
\hline SERM use & $1393(9.8)$ & $457(8.4)$ & $238(9.7)$ & $698(11.0)$ & $<.001$ \\
\hline Calcitonin & $9(0.1)$ & $4(0.1)$ & $3(0.1)$ & $2(0.0)$ & .29 \\
\hline Denosumab & $5(0.0)$ & $2(0.0)$ & $1(0.0)$ & $2(0.0)$ & .97 \\
\hline Hormone therapy & 1794 (12.6) & $687(12.6)$ & $317(13.0)$ & $790(12.4)$ & .75 \\
\hline
\end{tabular}

$P$ values for frequencies obtained from chi-square tests; $P$ values for mean age and mean Deyo CCI scores obtained from ANOVA $F$ test

$A N O V A$ analysis of variance, $B M D$ bone mineral density, $C C I$ Charlson comorbidity index, $M P R$ medication possession ratio, $O P$ osteoporosis, $S D$ standard deviation, SERM selective estrogen receptor modulator

artery had a statistically significant difference across persistence groups but not for adherence groups. However, even where statistically significant differences were found, the incidence patterns generally were not consistent across the exposure groups, as increases and decreases in incidence were observed with longer persistence. There were no statistically significant differences estimated in any of the analyses for pneumonia-organism unspecified, obstructive chronic bronchitis with acute exacerbation, atrial fibrillation, or unspecified septicemia (see Online Resource 2, 3, 4).

\section{Discussion}

Evidence of therapy benefits under real-world clinical conditions, or real-world evidence, is becoming increasingly important to payers and health care providers as the need to allocate scarce budgets more efficiently and to improve patient outcomes intensifies. The current study uses a real-world US claims database to examine the relationship between teriparatide adherence and persistence and hip and other fracture incidences. The results show fracture incidence decreased as adherence or persistence increased for any, vertebral, nonvertebral, and hip fractures.
Hip fracture is an important clinical end point for osteoporosis medications. In many smaller studies, the hip fracture end point has not been examined because of insufficient numbers of events. A recent review of teriparatide use reported increases in cancellous bone volume, improvement in bone architecture, and increases in cortical thickness associated with increased cortical remodeling [41]. Additionally, teriparatide $20 \mu \mathrm{g} /$ day increased femoral neck and total hip BMD; the gains continued during ongoing treatment through 24 months [41]. The Direct Assessment of Nonvertebral Fractures in Community Experience (DANCE) study evaluated over 4000 men and women receiving teriparatide for 24 months who were then followed up for an additional 24 months after treatment $[41,22]$. The incidence of patients experiencing a new nonvertebral fragility fracture was 1.42 , $0.91,0.70$, and $0.81 \%$ for the $0-6-, 6-12-, 12-18-$, and $18-24-$ month treatment periods, and this trend persisted after teriparatide treatment was discontinued [22, 41]. Hip fractures as a percentage of patients at risk decreased as treatment duration increased $0.27 \%$ (10/3720 patients), $0.067 \%$ (2/3010 patients), $0.15 \%$ ( $4 / 2629$ patients), and $0 \%$ (0/2287 patients) for the 0-6-, 6-12-, 12-18-, and 18-24-month treatment periods [41]. 
Table 2 Baseline characteristics by persistence group

\begin{tabular}{|c|c|c|c|c|c|c|}
\hline & \multirow[b]{2}{*}{$\begin{array}{l}\text { Total } \\
(N=14,284)\end{array}$} & \multirow[b]{2}{*}{$\begin{array}{l}1-6 \text { months } \\
(N=3916)\end{array}$} & \multicolumn{3}{|l|}{ Persistence } & \multirow[b]{2}{*}{$P$ value } \\
\hline & & & $\begin{array}{l}7-12 \text { months } \\
(N=1968)\end{array}$ & $\begin{array}{l}13-18 \text { months } \\
(N=1842)\end{array}$ & $\begin{array}{l}19-24 \text { months } \\
(N=6558)\end{array}$ & \\
\hline \multicolumn{7}{|l|}{ Age, years } \\
\hline Age, mean (SD) & $68.35(12.01)$ & $67.46(13.08)$ & $67.08(12.28)$ & $67.67(11.94)$ & $68.86(11.21)$ & $<.001$ \\
\hline Age group, $N(\%)$ & & & & & & $<.001$ \\
\hline $18-44$ & $284(2.0)$ & $133(3.4)$ & $44(2.2)$ & $39(2.1)$ & $68(1.0)$ & \\
\hline $45-54$ & $1445(10.1)$ & $440(11.2)$ & $267(13.6)$ & $189(10.3)$ & $549(8.4)$ & \\
\hline $55-64$ & $4220(29.5)$ & $1029(26.3)$ & $606(30.8)$ & $599(32.5)$ & $1986(30.3)$ & \\
\hline $65-74$ & $3299(23.1)$ & $821(21.0)$ & $424(21.5)$ & $414(22.5)$ & $1640(25.0)$ & \\
\hline $75-84$ & $3845(26.9)$ & $1084(27.7)$ & 485 (24.6) & $457(24.8)$ & $1819(27.7)$ & \\
\hline$\geq 85$ & $1191(8.3)$ & $409(10.4)$ & $142(7.2)$ & $144(7.8)$ & $496(7.6)$ & \\
\hline \multicolumn{7}{|l|}{ Sex, $N(\%)$} \\
\hline Female & $12,822(89.8)$ & $3501(89.4)$ & $1780(90.4)$ & $1662(90.2)$ & 5879 (89.6) & .55 \\
\hline Male & $1462(10.2)$ & $415(10.6)$ & $188(9.6)$ & $180(9.8)$ & $679(10.4)$ & \\
\hline \multicolumn{7}{|l|}{ Clinical characteristics } \\
\hline BMD test (yes/no), $N(\%)$ & $11,722(82.1)$ & $3003(76.7)$ & $1586(80.6)$ & $1559(84.6)$ & $5574(85.0)$ & $<.001$ \\
\hline Previous fracture (yes/no), $N(\%)$ & 4235 (29.6) & $1162(29.7)$ & $562(28.6)$ & $575(31.2)$ & $1936(29.5)$ & .34 \\
\hline Deyo CCI, mean (SD) & $0.99(1.42)$ & $1.15(1.50)$ & $0.99(1.47)$ & $1.00(1.41)$ & $0.90(1.35)$ & $<.001$ \\
\hline \multicolumn{7}{|l|}{ Confounding medication, $N(\%)$} \\
\hline Glucocorticoids & $5872(41.1)$ & $1773(45.3)$ & $841(42.7)$ & $745(40.4)$ & $2513(38.3)$ & $<.001$ \\
\hline Hormone deprivation & $154(1.1)$ & $45(1.1)$ & $17(0.9)$ & $22(1.2)$ & $70(1.1)$ & .74 \\
\hline Anticonvulsants & $2450(17.2)$ & $763(19.5)$ & $362(18.4)$ & $337(18.3)$ & $988(15.1)$ & $<.001$ \\
\hline Immunosuppressants & $1367(9.6)$ & $388(9.9)$ & $202(10.3)$ & $179(9.7)$ & $598(9.1)$ & .36 \\
\hline \multicolumn{7}{|l|}{ Other OP medication, $N(\%)$} \\
\hline Bisphosphonates & $7392(51.8)$ & $1668(42.6)$ & $901(45.8)$ & $958(52.0)$ & $3865(58.9)$ & $<.001$ \\
\hline SERM & $1393(9.8)$ & $312(8.0)$ & $188(9.6)$ & $173(9.4)$ & $720(11.0)$ & $<.001$ \\
\hline Calcitonin & $9(0.1)$ & $3(0.1)$ & $1(0.1)$ & $2(0.1)$ & $3(0.0)$ & .78 \\
\hline Denosumab & $5(0.0)$ & $2(0.1)$ & 0 & $1(0.1)$ & $2(0.0)$ & .75 \\
\hline Hormone therapy & 1794 (12.6) & $488(12.5)$ & $263(13.4)$ & $241(13.1)$ & $802(12.2)$ & .51 \\
\hline
\end{tabular}

$P$ values for frequencies obtained from chi-square tests; $P$ values for mean age and mean Deyo CCI scores obtained from ANOVA $F$ test ANOVA analysis of variance, $B M D$ bone mineral density, $C C I$ Charlson Comorbidity Index, $O P$ osteoporosis, $S D$ standard deviation, $S E R M$ selective estrogen receptor modulator

In $\mathrm{Yu}$ and colleagues' study, hip fracture incidence appeared to decrease with longer exposure, though in multivariate models the association of teriparatide exposure and incidence did not reach statistical significance (persistence 1-6 vs 19-24 months: $\mathrm{OR}=1.93$; $P=.08$ ). Our study extends the work of Yu and colleagues by using a larger and more recent database and by applying Cox proportional hazard models with timedependent covariates for cumulative teriparatide exposure to show the effect of adherence to therapy on fracture incidence. Our study is the first to demonstrate real-world effectiveness of teriparatide in reducing the risk of hip and other fragility fractures in the USA.

The wrist has proven to be a difficult site for which to demonstrate reduced fracture risk in studies of osteoporosis because high forces are applied to the wrist as people brace themselves with their hands when falling, so it is common for people with healthy bones to experience wrist fractures. Clinical trials of osteoporosis drugs have shown inconsistent effects on wrist fractures or not reported this outcome [42]. Our study reveals an inconsistent reduction in wrist fractures by MPR and persistence categories using logistic and Cox regressions; statistical significance was not achieved. The fact that increased teriparatide adherence and persistence did not significantly reduce wrist fracture risk might relate to teriparatide increasing cortical remodeling [41] and decreasing bone mineral density at the radius [15], although teriparatide increases cortical thickness [41]. Alternatively, the lack of significance might be due to an insufficient number of wrist fractures; future analyses with larger numbers of events may clarify the effect of teriparatide at this site.

The study's limitations include those typical when claims databases are used, including lack of randomization, potential miscoding of the fracture type or overestimating or underestimating the fracture incidences; use of algorithms whose validity and reliability have not been established to identify incident fractures; lack of information on clinical risk factors (e.g., limited medical history, no family medical history, lifestyle risk factors, no BMD T scores); and the inability to ascertain actual patient adherence (e.g., proper injections) to therapy. In observational studies examining osteoporosis 
A

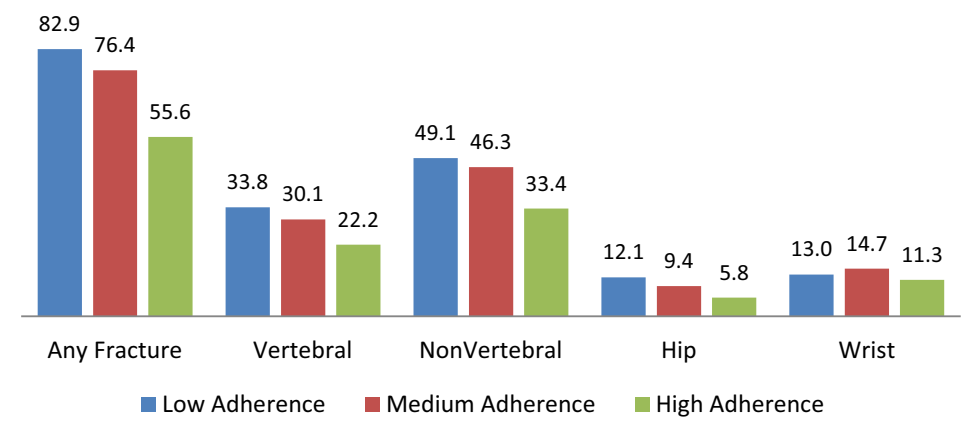

Analysis of variance (ANOVA) F-tests across medication possession ratio (MPR) groups showed significant differences for all fracture categories $(\mathrm{p}<.0001)$ except wrist $(\mathrm{p}=.169)$.

An MPR greater than or equal to 0.80 was defined as high, $0.50 \leq \mathrm{MPR}<0.80$ was defined as medium, and $<0.50$ was defined as low adherence for osteoporosis medication

B

91.2

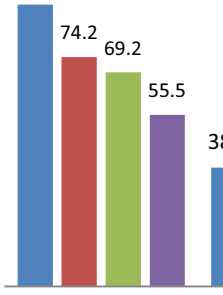

Any Clinical

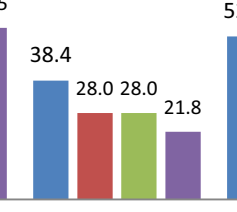

Vertebral

52.7

46.241 .3

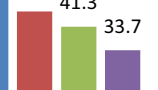

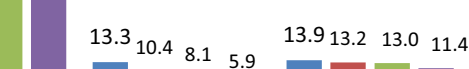

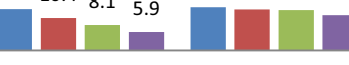

1-6 months 7-12 months 13-18 months $\quad$ 19-24 months

Analysis of variance (ANOVA) F-tests across persistence groups showed significant differences for all fracture categories ( $<<.0001)$ except wrist $(p=.424)$.

Persistence was defined as continuous use of teriparatide during the indicated time interval.

Fig. 2 Fracture incidence per 1000 patient years

therapy adherence and healthy adherer bias, only limited evidence was found [39, 43]. In one study on Medicare patients, the association between high adherence with different medications (oral bisphosphonates, selective serotonine re-uptake inhibitors, angiotensin converting enzyme inhibitors, and calcium channel blockers) and fracture was examined to test for possible healthy adherer bias; and the authors concluded that the healthy adherer effect was limited [39]. Another study examined the potential for healthy adherer bias in elderly Medicaid patients in Pennsylvania by estimating the association between adherence to osteoporosis therapies (raloxifene, calcitonin, oral bisphosphonates) and subsequent vaccination and health care testing [43]. The authors reported there was limited evidence of a healthy adherer effect, although higher adherence with raloxifene was associated with higher fracture risk and was probably due to residual confounding in those patients [43]. In our study, we examined six separate control outcomes and found mixed results and thus did not detect any strong evidence of healthy adherer bias. Nevertheless, we cannot conclusively claim absence of healthy adherer effects or bias within our estimates, though any such impacts would appear to be minimal. The use of osteoporosis medications known to reduce fracture risk after stopping teriparatide may represent a bias against showing teriparatide effectiveness in this analysis. Additionally, claims for incident fractures, especially with respect to incident compression vertebral fractures may be incorrect, and misclassification of outcomes may also represent a bias reducing the association of adherence with fracture risk reduction [44].

In summary, teriparatide stimulates bone formation at the femur by histology, bone scan, and PET scan and has proven to increase femoral neck and total hip BMD [41, 45]. Clinical, observational, and claims database studies show fewer nonvertebral fractures (a composite end point including hip fractures) with longer teriparatide treatment than with shorter teriparatide treatment. The DANCE study and Yu and colleagues' claims database study show apparent decreases in numbers of hip fractures with longer than with shorter teriparatide treatment, although statistical significance was not reached in the $\mathrm{Yu}$ and colleagues study. Our study, with a larger sample of teriparatide-treated patients, confirms a 


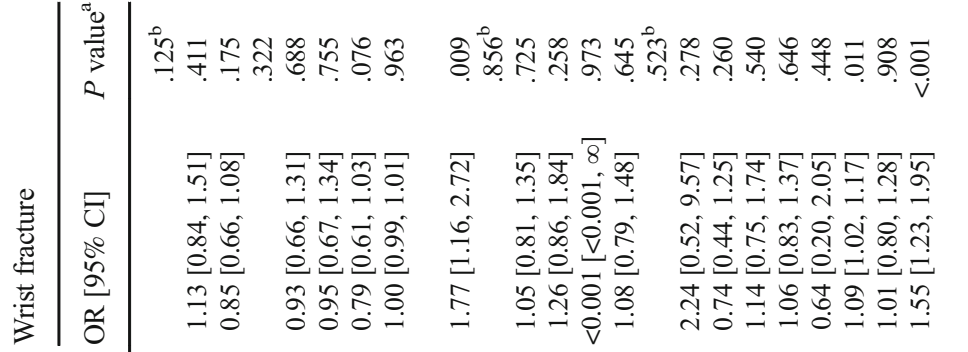

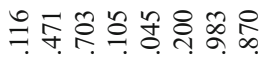

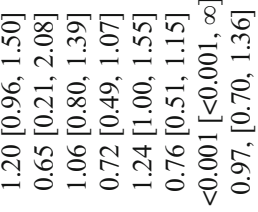

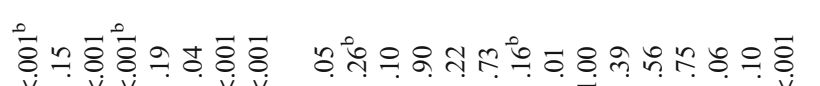

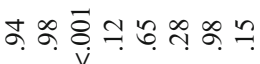

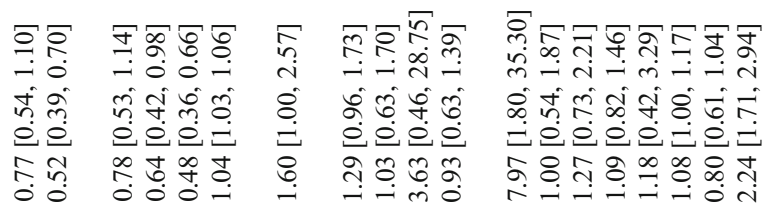

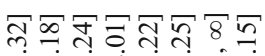

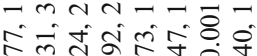

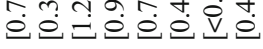

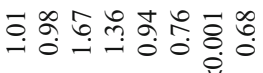

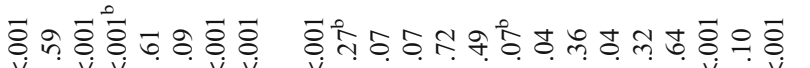

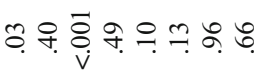

鹿



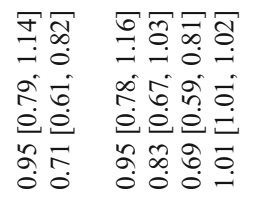

হ్

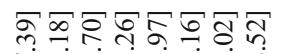

๓ฺ

की

त्

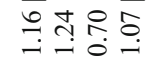

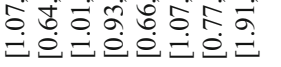

त)

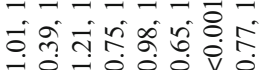

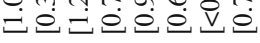

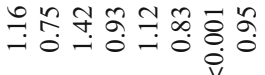

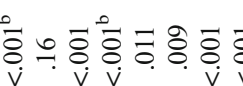

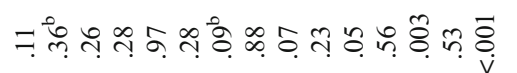

จุ

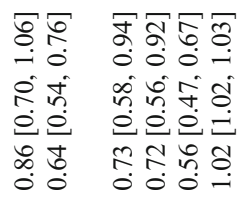

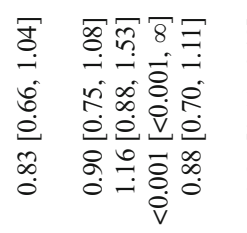

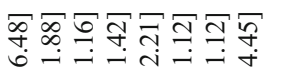

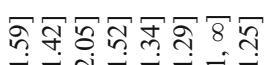

숭

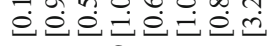

مึ

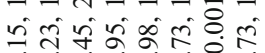

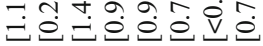

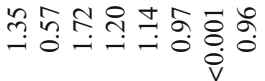

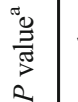

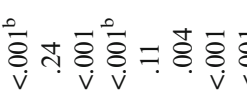

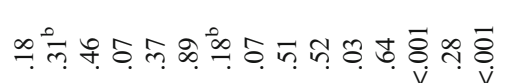

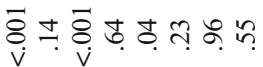

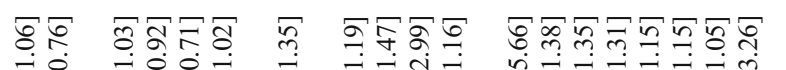

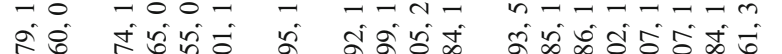

จं से है

응 0

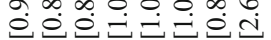

กิธ

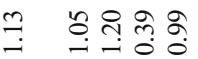

ते

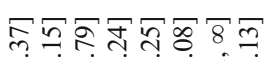

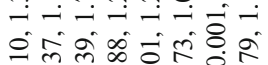

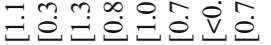

तิ

(1)
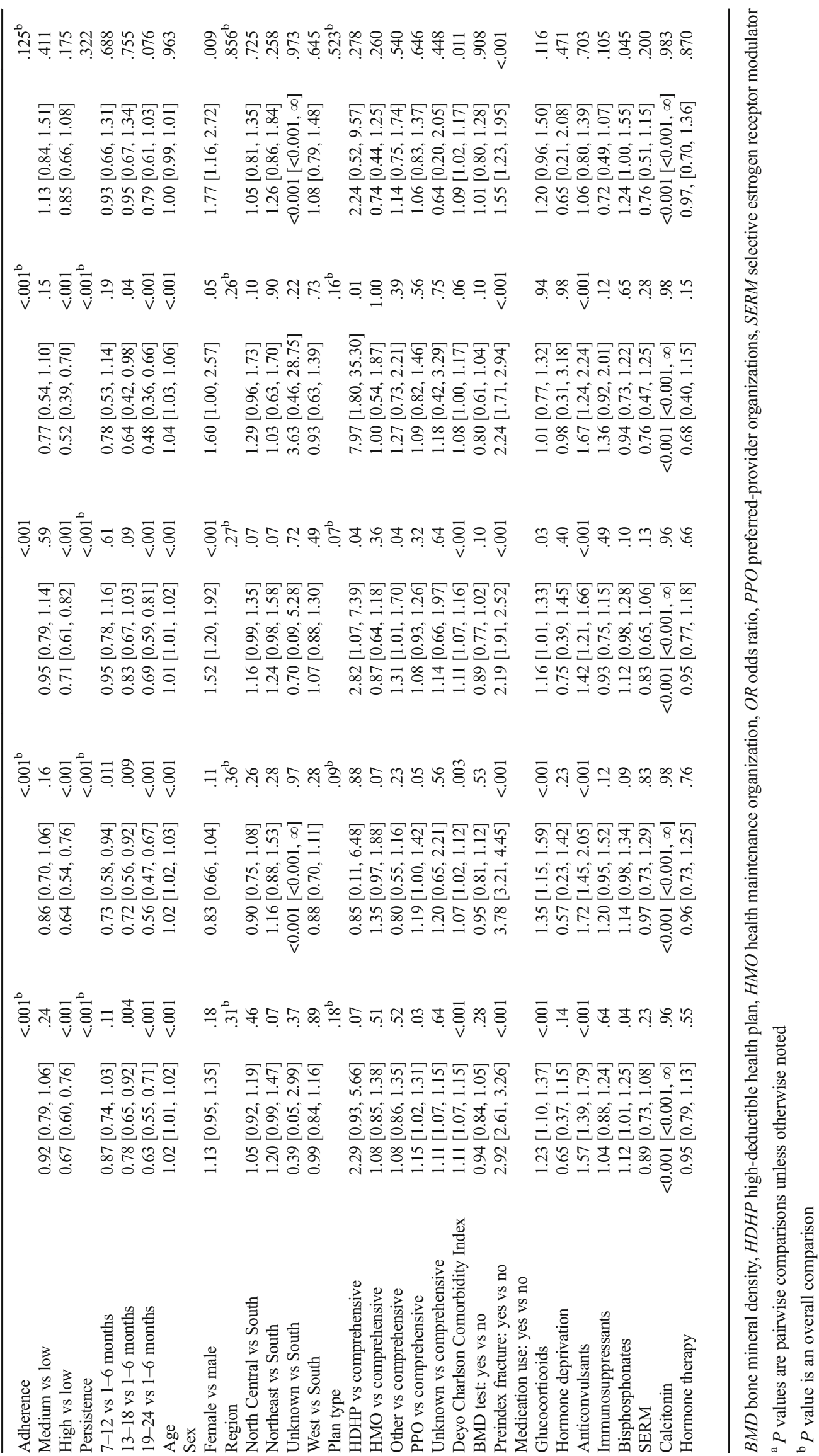
statistically significant reduction in hip and other fragility fractures with longer persistence or higher adherence.

\section{Conclusion}

This study is the first to demonstrate real-world effectiveness of teriparatide to reduce the risk of hip fractures along with other fragility fractures in the USA. Among teriparatide patients in a US claims database who were observed for 2 years after teriparatide initiation, fracture incidence significantly decreased as adherence and persistence increased for vertebral, nonvertebral, hip, and any clinical fractures.

Acknowledgements We wish to acknowledge the assistance of Christina Webb and Christopher Konkoy for preparation of the manuscript. We also are grateful to Dr. Jeffrey Curtis for his methodological guidance on the healthy adherer bias analyses.

Compliance with ethical standards

Funding The study was funded by Eli Lilly and Company.

Conflict of interest All authors are employees of Eli Lilly and Company and minor stockholders.

Ethical approval For this type of study, formal consent is not required (retrospective study).

Open Access This article is distributed under the terms of the Creative Commons Attribution-NonCommercial 4.0 International License (http://creativecommons.org/licenses/by-nc/4.0/), which permits any noncommercial use, distribution, and reproduction in any medium, provided you give appropriate credit to the original author(s) and the source, provide a link to the Creative Commons license, and indicate if changes were made.

\section{References}

1. National Osteoporosis Foundation. What is osteoporosis? https://www.nof.org/patients/what-is-osteoporosis/. Accessed 18 May 2016

2. National Osteoporosis Foundation. Clinician's guide to prevention and treatment of osteoporosis. Washington, DC: National Osteoporosis Foundation; 2013

3. Burge R, Dawson-Hughes B, Solomon DH, Wong JB, King A, Tosteson A (2007) Incidence and economic burden of osteoporosis-related fractures in the United States. J Bone Miner Res 22(3):465-475

4. Melton LJ 3rd, Crowson CS, O'Fallon WM (1999) Fracture incidence in Olmsted County, Minnesota: comparison of urban with rural rates and changes in urban rates over time. Osteoporos Int 9(1):29-37

5. Brauer CA, Coca-Perraillon M, Cutler DM, Rosen AB (2009) Incidence and mortality of hip fractures in the United States. JAMA 302(14):1573-1579 
6. Leslie WD, O'Donnell S, Jean S, Lagacé C, Walsh P, Bancej C, Morin S, Hanley DA, Papaioannou A (2009) Trends in hip fracture rates in Canada. JAMA 302(8):883-889

7. Kannus P, Niemi S, Parkkari J, Palvanen M, Vuori I, Jävinen M (2006) Nationwide decline in incidence of hip fractures. J Bone Miner Res 21(12):1836-1838

8. Nymark T, Lauritsen JM, Ovesen O, Röck ND, Jeune B (2006) Decreasing incidence of hip fracture in the Funen County, Denmark. Acta Orthop 77(1):109-113

9. Dimai HP, Svedbom A, Fahrleitner-Pammer A, Pieber T, Resch H, Zwettler E, Chandran M, Borgström F (2010) Epidemiology of hip fractures in Austria: evidence for a change in the secular trend. Osteoporos Int 22(2):685-692

10. Magaziner J, Simonsick EM, Kashner TM, Hebel JR, Kenzora JE (1990) Predictors of functional recovery one year following hospital discharge for hip fracture: a prospective study. J Gerontol 45(3):M101-M107

11. Magaziner J, Hawkes W, Hebel JR, Zimmerman SI, Fox KM, Dolan M, Felsenthal G, Kenzora J (2000) Recovery from hip fracture in eight areas of function. J Gerontol A Biol Sci Med Sci 55(9): M498-M507

12. van Staa TP, Leufkens HGM, Cooper C (2002) Does fracture at one site predict later fractures at other sites? A British cohort study. Osteoporos Int 13(8):624-629

13. Binder EF, Brown M, Sinacore DR, Steger-May K, Yarasheski KE, Schechtman KB (2004) Effects of extended outpatient rehabilitation after hip fracture. A randomized controlled trial. JAMA 292(7): 837-846

14. Bhandari M, Tornetta P 3rd, Hanson B, Swiontkowski MF (2009) Optimal internal fixation for femoral neck fractures: multiple screws or sliding hip screws. J Orthop Trauma 23:403-407

15. Neer RM, Arnaud CD, Zanchetta JR, Prince R, Gaich GA, Reginster JY, Hodsman AB, Eriksen EF, Ish-Shalom S, Genant HK, Wang O, Mitlak BH (2001) Effect of parathyroid hormone (1-34) on fractures and bone mineral density in postmenopausal women with osteoporosis. N Engl J Med 344(19):1434-1441

16. Orwoll ES, Scheele WH, Paul S, Adami S, Syversen U, Diez-Perez A, Kaufman JM, Clancy AD, Gaich GA (2003) The effect of teriparatide [human parathyroid hormone (1-34)] therapy on bone density in men with osteoporosis. J Bone Miner Res 18(1):9-17

17. Keaveny TM, Donley DW, Hoffmann PF, Mitlak BH, Glass EV, San Martin JA (2007) Effects of teriparatide and alendronate on vertebral strength as assessed by finite element modeling of QCT scans in women with osteoporosis. J Bone Miner Res 21:149-157

18. Forteo [package insert]. Indianapolis, IN: Eli Lilly and Company; 2010

19. Forsteo [Summary of Product Characteristics]. Eli Lilly Nederland B.V. 2010

20. Lindsay R, Miller P, Pohl G, Glass EV, Chen P, Krege JH (2009) Relationship between duration of teriparatide therapy and clinical outcomes in postmenopausal women with osteoporosis. Osteoporos Int 20(6):943-948

21. Langdahl BL, Rajzbaum G, Jakob F, Karras D, Ljunggren Ö, Lems WF, Fahrleitner-Pammer A, Walsh JB, Barker C, Kutahov A, Marin F (2009) Reduction in fracture rate and back pain and increased quality of life in postmenopausal women treated with teriparatide: 18-month data from the European Forsteo Observational Study (EFOS). Calcif Tissue Int 85(6):484-493

22. Silverman S, Miller P, Sebba A, Weitz M, Wan X, Alam J, Mascia D, Taylor KA, Ruff VA, Krohn K (2013) The direct assessment of nonvertebral fractures in community experience (DANCE) study: 2-year nonvertebral fragility fracture results. Osteoporos Int 24(8):2309-2317
23. Yu S, Burge RT, Foster S, Gelwicks S, Meadows E (2012) The impact of teriparatide adherence and persistence on fracture outcomes. Osteoporos Int 23(3):1102-1113

24. Seeman E, Compston J, Adachi J, Brandi ML, Cooper C, Dawson-Hughes B, Jönsson B, Pols H, Cramer JA (2007) Non-compliance: the Achilles' heel of anti-fracture efficacy. Osteoporos Int 18(6):711-719

25. Siris ES, Harris ST, Rosen CJ, Barr CE, Arvesen JN, Abbott TA, Silverman S (2006) Adherence to bisphosphonate therapy and fracture rates in osteoporotic women: relationship to vertebral and nonvertebral fractures from 2 US claims databases. Mayo Clin Proc 81(8):1013-1022

26. Siris E, Selby P, Saag KG, Borgström F, Herings R, Silverman SL (2009) Impact of osteoporosis treatment adherence on fracture rates in North America and Europe. Am J Med 122(2 Suppl):S3-S13

27. Penning-van Beest FJ, Erkens JA, Olson M, Herings RM (2008) Loss of treatment benefit due to low compliance with bisphosphonate therapy. Osteoporos Int 19(4):511-517

28. Weycker D, Macarios D, Edelsberg J, Oster G (2007) Compliance with osteoporosis drug therapy and risk of fracture. Osteoporos Int 18(3):271-277

29. Halpern R, Becker L, Iqbal SU, Kazis LE, Macarios D, Badamgarav E (2011) The association of adherence to osteoporosis therapies with fracture, all-cause medical costs, and all-cause hospitalizations: a retrospective claims analysis of female health plan enrollees with osteoporosis. J Manag Care Pharm 17(1):25-39

30. Cheng LI, Durden E, Limone B, Radbill L, Juneau PL, Spangler L, Mirza FM, Stolshek BS (2015) Persistance and compliance with osteroporosis therapies among women in a commercially insured population in the United States. J Manag Care Spec Pharm 21(9):824-833

31. Foster SA, Foley KA, Meadows ES, Johnston JA, Wang SS, Pohl GM, Long SR (2011) Adherence and persistence with teriparatide among patients with commercial, Medicare, and Medicaid insurance. Osteoporos Int 22(2):551-557

32. Chan DC, Chang CH, Lim LC, Brnabic AJ, Tsauo JY, Burge R, Hsiao FY, Jin L, Gürbiüz S, Yang RS (2016) Association between teriparatide treatment duration and fracture incidence in Taiwan: analysis using the National Health Insurance Research Database. Osteoporosis Int. doi:10.1007/s00198-016-3611-x

33. Boytsov N, Zhang X, Sugihara T, Taylor K, Swindle R (2015) Osteoporotic fractures and associated hospitalizations among patients treated with teriparatide compared to a matched cohort of patients not treated with teriparatide. Curr Med Res Opin 31(9): 1665-1675

34. Bonafede MM, Shi N, Bower AG, Barron RL, Grauer A, Chandler DB (2015) Teriparatide treatment patterns in osteoporosis and subsequent fracture events: a US claims analysis. Osteoporos Int 26(3): $1203-1212$

35. Krege JH, Burge RT, Marin F (2015) Teriparatide fracture effectiveness in the real world. Osteoporos Int 26(8):2217-2218

36. Lee RH, Lyles KW, Colon-Emerec C (2010) A review of the effect of anticonvulsant medications on bone mineral density and fracture risk. J Am Ger Soc 8(1):34-46

37. Petty SJ, O'Brien TJ, Wark JD (2007) Anti-epileptic medication and bone health. Osteoporos Int 18(2):129-142

38. Warriner AH, Patkar NM, Curtis JR, Delzell E, Gary L, Kilgore M, Saag K (2011) Which fractures are most attributable to osteoporosis? J Clin Epidemiol 64(1):46-53

39. Curtis JR, Yun H, Lange JL, Matthews R, Sharma P, Saag KG, Delzell E (2012) Does medication adherence itself confer fracture protection? An investigation of the healthy adherer effect in observational data. Arthritis Care Res 64(12):1855-1863. doi:10.1002 /acr.21759 
40. Patrick AR, Shrank WH, Glynn RJ, Solomon DH, Dormuth CR, Avorn J, Cadarette SM, Mogun H, Brookhar MA (2011) The association between statin use and outcomes potentially attributable to an unhealthy lifestyle in older adults. Value Health 14:513-520

41. Eriksen E, Keaveny TM, Gallagher ER, Krege JH (2014) Literature review: the effects of teriparatide at the hip in patients with osteoporosis. Bone 67:246-256

42. Hopkins RB, Goeree R, Pullenayegum E, Adachi JD, Papaioannou A, Xie F, Thabane L (2011) The relative efficacy of nine osteoporosis medications for reducing the rate of fractures in post-menopausal women. BMC Musculoskelet Disord 12:209
43. Cadarette SM, Solomon DH, Katz JN, Patrick AR, Brookhart MA (2011) Adherence to osteoporosis drugs and fracture prevention: no evidence of healthy aderer bias in a frail cohort of seniors. Osteoporos Int 22:943-954

44. Curtis JR, Mudano AS, Solomon DH, Xi J, Melton ME, Saag KG (2009) Identification and validation of vertebral compression fractures using administrative claims data. Med Care 47(1):69-72

45. Cosman F, Dempster DW, Nieves JW, Zhou H, Zion M, Roimisher C, Houle Y, Lindsay R, Bostrom M (2016) Effect of teriparatide on bone formation in the human femoral neck. J Clin Endocrinol Metab 101(4):1498-1505 